Violence and Community:

Collective and Cultural Trauma in Black America

Michael Yu

Boston College School of Theology and Ministry

November 5, 2015 


\begin{abstract}
The relationship between law enforcement and predominantly black communities has been characterized by mistrust, violence, and victimization. Recently, this issue has entered into the national conversation, sparked by the deaths of Michael Brown, Eric Garner, Sandra Bland, Samuel Dubose, Tamir Rice, Laquan McDonald, and countless other black individuals. The present paper presents the experience of black communities in the United States as an experience of collective and communal trauma. First, collective trauma is conceptualized and distinguished from individual trauma writ large from a sociological perspective with Ignacio Martin Baró and Jeffrey Alexander. Communal trauma is a phenomenon that is different than individual trauma because of its social and communal implications. Next, the experience of black communities in light of consistent patterns of police violence is named as collective trauma. Michelle Alexander's The New Jim Crow will be used, as well as Atlantic correspondent Ta-Nehisi Coates. The final section proposes a pastoral response to the communal trauma of Black communities, divided into two parts. The first is a look inwards towards organized Christianity's complicity in the terrorism of Black communities and the benefits that are gained from their subjugation, and the second looks outwards, proposing a stance of solidarity, courage, and righteous indignation that actively works towards the liberation of marginalized communities.
\end{abstract}




\section{Violence and Community}

Black people in the United States have been enslaved for longer than they have been free. For centuries, a significant part of the economy of the United States was built on human labor, extracted through torture and subjugation. Today, race continues to be a contentious issue in the United States, and Black communities continue to suffer from collective and cultural trauma. While collective trauma may share some characteristics of individual trauma (and appear to be multiple cases of individual trauma in a geographic cluster), the way that trauma is viewed, conceptualized, and politicized makes understanding community trauma as a separate and unique phenomenon immensely important for addressing the various needs of the suffering communities. Especially for trauma that centers on issues of race, collective trauma must be acknowledged and affirmed in response to movements that politicize and decontextualize the Black American experience with racist, white supremacist ideologies. These ideologies metastasize onto mainstream culture to promote injustice, subjugation, violence, and murder.

As a brief note, within the present paper the terms social, collective, and cultural trauma will be used interchangeably to refer to sociologist Kai Erikson's definition of collective trauma as "when members of a collectivity feel they have been subjected to a horrendous event that leaves indelible marks upon their group consciousness, marking their memories forever and changing their future identity in fundamental and irrevocable ways."1

\section{Collective and Cultural Trauma}

\footnotetext{
${ }^{1}$ Kai Erikson, as quoted by Jeffrey Alexander, Trauma: A Social Theory (Cambridge: Polity Press, 2012 ), 6.
} 
Jesuit priest and martyr Ignacio Martín-Baró assesses the individual model of Trauma and PTSD as being insufficient in Writings for a Liberation Psychology. Informed by experiences of the El Salvadorian Civil War, Martín-Baró argues that trauma affects the social aspects of an individual and in turn society at large. Trauma is not only on an individual level, like a injury or laceration. ${ }^{2}$ Collective trauma affects a system of people, as opposed to a number of people. He argues that under this proposed psychosocial concept, two specific characteristics emerge. First, trauma is seen as socially produced, and addressing it requires treating the root causes of trauma (which are inherently social). ${ }^{3}$ Second, trauma becomes chronic when the societal factors that create it persist — in addition to being socially caused, it is socially maintained. Trauma is the "concrete crystallization in individuals of aberrant and dehumanizing social relations."4 MartínBaró's assertions regarding trauma are just as applicable to the experiences of marginalized Black communities in the United States as they are for children victimized in the Salvadorian Civil War-racism and police violence is socially created and socially sustained. Such trauma establishes a culture of fear that affects the psychosocial wellbeing of communities of all types, and the individual, clinical model of Post Traumatic Stress Disorder insufficiently addresses this phenomenon of trauma.

Sociologist Jeffrey Alexander engages collective trauma and offers insights into the advantages of adopting the concept of collective trauma. Alexander identifies that cultural trauma, unlike widespread instances of PTSD, is a concept that brings aspects of human

\footnotetext{
${ }^{2}$ Ignacio Martín-Baró, Writings for a Liberation Psychology (Cambridge, MA: Harvard University Press, 1994), 123.

${ }^{3}$ Ibid., 125.

${ }^{4}$ Ibid.
} 
suffering into the domain of trauma. Members of a society that are confronted with the cultural trauma of another group are pulled into solidarity, so that cultural trauma engenders a sense of social responsibility in a way a collection of PTSD cases does not. ${ }^{5}$ Inversely, when cultural trauma is individualized, politicized, and not truly recognized, solidarity and responsibility can wither. Alexander defines of collective trauma as damage to the connections and fabric that hold a community together. Individuals who experience collective trauma realize that "the community no longer exists as an effective source of support and that an important part of the self has disappeared." ${ }^{6}$ In this sense, collective trauma reflects psychologist Jon G. Allen's understanding of trauma as an event (or events) with objective and subjective aspects. Subjectively, individuals who experience trauma experience feelings of fear, helplessness, or horror and have lasting impressions that one's body is no longer secure, ${ }^{7}$ and communities that experience trauma do not feel that the communities are secure. Understanding this sense of danger and fear that pervades communities is paramount to understanding and addressing collective trauma. By acknowledging the reality of cultural trauma, the broader society is brought towards a stance of solidarity, responsibility, and indeed, reconciliation.

Contextualizing collective trauma in order to address it responsibly as a society and as a Church is incredibly important. Without a firm grasp and acknowledgment of the phenomenon, caregivers can fall into a neo-liberal trap of seeing mental illness epidemics as a cluster of

\footnotetext{
${ }^{5}$ Alexander, Trauma, 6.

${ }^{6}$ Ibid., 9.

${ }^{7}$ Jon G. Allen, Coping with Trauma: Hope Through Understanding. (Arlington, VA: American Psychiatric Publishing, Inc., 2005), 4.
} 
individually contained neurological pathologies. ${ }^{8}$ Conceptualizing trauma on an individual model fails to address injustice and engender solidarity, and in its pathologizing, it ultimately serves the interests of the established order. By saying that Black communities are not collectively traumatized and instead experience higher than average clusters of discrete episodes of PTSD, the best practice treatment approach becomes mental health counseling without of structural and socio-political reform. The clinical trauma model addresses an individual instance of PTSD, but it fails to challenge those who benefit from the established order.

\section{Black Communities and Police Violence}

Jeffrey Alexander's model of community trauma acknowledges a traumatized community as one in which the community itself recognizes that it is no longer a safe place to be-the social fabric and connections have been damaged, typically by external forces. ${ }^{9}$ Black communities in cities across the United States have experienced these social ruptures on a consistent basis for decades. Between Jim Crow laws, the War on Drugs, redlining, police brutality, and community violence, black communities have sustained repeated blow trauma over the course of decades. In the present paper, attention will be directed to one specific issue: police brutality, a racially

\footnotetext{
${ }^{8}$ For further reading, see Bruce Rogers Vaughn "Blessed Are Those Who Mourn: Depression as Political Resistance." Pastoral Psychology, 63, no. 4 (2014): 503-522.

${ }^{9}$ Alexander, Trauma, 9.
} 
motivated type of political violence and domestic terrorism, used and endorsed by the state for the political end of the subjugation of Black Americans and Black communities. ${ }^{10}$

There are undoubtedly political ends to the War on Drugs, the mass incarceration of black men in the United States, and the effects these policies have on Black communities. Michelle Alexander provides the most significant evidence of this claim. Regarding an increase in national drug use she states, "[F]or reasons traceable largely to racial politics and fear mongering we chose war. Conservatives found they could finally justify an all-out war on an "enemy" that had been racially defined years before." 11 The Reagan administration pumped millions of dollars into the War on Drugs and associated policies, militarizing police and incentivizing force and the redirection of resources towards criminalization, prosecution, and incarceration. ${ }^{12}$ The War on Drugs was racially motivated —of this there is no question. Although blacks were more likely to be the victims of drug related crimes, whites supported the War on Drugs more. ${ }^{1314}$ The racial subjugation of these individuals became the racial subjugation of communities. This subjugation at the hands of the police is part of a larger system of injustice and violence suffered by Black communities nationwide. The murder of Freddie Gray, Eric Garner, and Laquan McDonald at the hands of the police was yet another act of violence and terrorism in a crowded historical tapestry

\footnotetext{
10 The FBI defines domestic terrorism as an act that meets three criteria: first, it involves acts dangerous to human life that violate federal or state law. Second, the act must appear intended to intimidate or coerce a civilian population, and finally it must occur primarily within the territorial jurisdiction of the United States.

${ }^{11}$ Michelle Alexander, The New Jim Crow (New York: The New Press, 2011), 52.

12 Ibid.,

${ }^{13}$ Ibid., 54.

14 Ibid. 58.
} 
of racism that unilaterally told Black communities in the United States that their bodies are not safe, their families are not safe, and their communities are certainly and terrifyingly unsafe.

Systemically, politically, socially, and economically, for Black communities, the community is not a safe place to be. The agents of the state tasked with safety of the community are in fact agents of a state that systematically devalues the lives of members within the community. In an Atlantic article in response to the violence following Freddie Gray's murder, Ta-Nehisi Coates asserts, "Maryland prioritizes the protection of police officers charged with abuse over the citizens who fall under its purview."15 The community understands that the police, and by extension all agents of the state, are not to be respected and obeyed, but feared. The system that Black communities know in Baltimore is one of a "hollow law and failed order."16 The violence that erupted in Baltimore following the death of Freddie Gray was not an isolated incident, or a collection of individuals with PTSD having a synchronized episode of emotional dysregulation - it was the outcry of a community that has been under the boot of the state for decades. It was the collective explosion of terror, anger, and violence sustained by decades of state terrorism.

\section{Pastoral Response}

It is necessary to assert that by no means should a pastoral response take precedence over the advocacy Black communities engage in for themselves, and by no means is an exclusively pastoral response in any way sufficient to address the deeply rooted racial issues that pervade

\footnotetext{
15 Ta-Nehisi Coates, "Nonviolence as Compliance.” The Atlantic, Apr. 27, 2015. 16 Ibid.
} 
every fiber of the collective consciousness of the United States. Rather, the present section seeks to offer two important courses of action. The first is to engage inwards and find where pastoral leaders are called to conversion—we are all culturally situated, but solidarity and empathy calls us out of these contexts towards the most marginalized. The second action is to be drawn outwards, to speak truth to power and critically evaluate the systems and establishments that benefit from the racial subjugation of black communities. Inherent in this movement is the development of the understanding that many religious institutions are part of the established order and in fact many communities of faith may benefit from the violence inflicted on Black communities.

Ignacio Martín-Baró's concept of psychosocial trauma asserts that trauma is socially caused and socially sustained. Pastoral leaders should delicately and honestly engage the questions of how black communities are victimized. The root of social trauma may very well be internalized racist attitudes and disordered attachments to the benefits that systematized racism yields - the poisonous fruit that this sin bears. Institutional racism that prevents Black communities from achieving self-determination by state sponsored terrorism that instills fear into the souls of black communities is a fundamental aspect of life in the United States that allows for beautiful suburbs with white picket fences, private schools, and gated communities. The systematic plunder of black communities economically benefits the dominant groups of society -White Americans. This is the poisonous fruit that we have sown, and pastoral leaders are not blameless in its consumption, or in the plunder of black communities.

How can pastoral leaders and caregivers respond to centuries of state violence against communities, much less one incident in a long string of victimizations? Pastoral leaders must 
adopt a stance of solidarity and righteous fury. Pastoral caregivers must convert and hold in their hearts a preferential option for the poor and oppressed, and they must acknowledge that God loves in a deep and special way those who are downtrodden and victimized. Pastoral leaders must speak out against violence, terror, subjugation, and racism, even when it threatens the established order. The fact of the matter is that many pastoral leaders do not speak out about the murder of Freddie Gray, of Michael Brown, Sandra Bland, Tamir Rice, Laquan McDonald, or Eric Garner. They are afraid of challenging the status quo - they are afraid of the response of their congregation and their superiors, a response born in fear and sustained by racism. Pastoral leaders must live in solidarity; they must acknowledge cultural trauma, and in doing so draw out social solidarity and social responsibility from within themselves and within their faith communities.

Pastoral responses in the immediate aftermath of violent eruptions differ from broader pastoral responses to sustained trends in subjugation. In the immediate aftermath, pastoral caregivers should approach the murder of someone like Freddie Gray as an act of terrorism against a community. In the wake of murders, acquittals, protests, and riots, pastoral caregivers should respond only with love, patience, and presence. Inherent in solidarity is a stance of empathy, understanding, reconciliation, and love. Pastoral caregivers must respond to the violence committed against Black communities in charity and hope, and with a sober awareness of God's love for the marginalized. Pastoral caregivers should view these communities as the body of Christ being unjustly crucified by the Romans of our time-indeed, the evil that hung men of color from trees by the neck and left their bloodied bodies sprawled out in the streets is the same evil that nailed Christ to the cross. Churches must stand on the side of the broken body 
of Christ, drinking in the sorrow and suffering that has destroyed and terrorized God's dearly beloved, but they must also stand in hope of resurrection and reconciliation. When spines are severed and bullets tear through bone and flesh and brain, the state is exacting a brutal subjugation of human beings in the interests of power, and the body of Christ is suffering. Collectively and culturally, black communities have been victimized, terrorized, and traumatized for decades. Black people in the United States have been enslaved for longer than they have been free.

Bibliography 
American Psychiatric Association, Diagnostic and Statistical Manual of Mental Disorders: DSM-5. 2013.

Alexander, Jeffrey C. Trauma: A Social Theory. Cambridge, MA: Polity Press, 2012.

Alexander, Michelle. The New Jim Crow: Mass Incarceration in the Age of Colorblindness. New York: The New Press, 2011.

Allen, Jon G. Coping With Trauma: Hope Through Understanding. Arlington, VA: American Psychiatric Publishing, Inc., 2005.

Coates, Ta-Nehisi. “Nonviolence as Compliance.” The Atlantic, April 27, 2015.

Federal Bureau of Investigation. "Definitions of Terrorism in the US Code." Accessed Nov. 1, 2015. https://www.fbi.gov/about-us/investigate/terrorism/terrorism-definition

Martín-Baró, Ignacio. Writings for a Liberation Psychology. Cambridge, MA: Harvard University Press, 1994.

Robben, Antonius C. G. M. \& Marcelo M. Suárez-Orozco. Cultures under Siege: Collective Violence and Trauma. Cambridge: Cambridge University Press, 2000. 